5. McElhinney L, Fooks AR, Featherstone C, Smith R, Morgan D. Hantavirus (Seoul virus) in pet rats: a zoonotic viral threat. Vet Rec. 2016;178:171-2. https:// doi.org/10.1136/vr.i817

6. Reynes JM, Carli D, Bour JB, Boudjeltia S, Dewilde A, Gerbier G, et al. Seoul virus infection in humans, France, 2014-2016. Emerg Infect Dis. 2017;23:973-7. https:/ / doi.org/ 10.3201/eid2306.160927

7. Hofmann J, Weiss S, Kuhns M, Zinke A, Heinsberger H, Kruger DH. Importation of human Seoul virus infection to Germany from Indonesia. Emerg Infect Dis. 2018;24:1099_ 102. https://doi.org/10.3201/eid2406.172044

8. Swanink C, Reimerink J, Gisolf J, de Vries A, Claassen M, Martens L, et al. Autochthonous human case of Seoul virus infection, the Netherlands. Emerg Infect Dis. 2018;24:2158-63. https://doi.org/10.3201/eid2412.180229

9. Weiss R, Meersch M, Pavenstädt HJ, Zarbock A. Acute kidney injury. Dtsch Arztebl Int. 2019;116:833-42.

10. Klempa B, Fichet-Calvet E, Lecompte E, Auste B, Aniskin V, Meisel H, et al. Hantavirus in African wood mouse, Guinea. Emerg Infect Dis. 2006;12:838-40. https://doi.org/10.3201/ eid1205.051487

Address for correspondence: Jörg Hofmann, Institute of Virology, Helmut-Ruska-Haus, Charité - Universitätsmedizin Berlin, Charitéplatz 1, 10117 Berlin; Germany. e-mail: joerg.hofmann@charite.de

\section{Pediatric Lyme Disease Biobank, United States, 2015-2020}

\author{
Lise E. Nigrovic, Desire N. Neville, Fran Balamuth, \\ Michael N. Levas, Jonathan E. Bennett, \\ Anupam B. Kharbanda, Amy D. Thompson, \\ John A. Branda, Aris C. Garro, the Pedi Lyme Net \\ Working Group

\begin{abstract}
Author affiliations: Boston Children's Hospital, Boston, Massachussetts, USA (L.E. Nigrovic); Children's Hospital of Pittsburgh, Pittsburgh, Pennsylvania, USA (D.N. Neville); Milwaukee Children's Hospital, Milwaukee, Wisonsin, USA (F. Balamuth); Children's Hospital of Philadelphia, Philadelphia, Pennsylvania, USA (M.N. Levas); Nemours/Alfred I. duPont Children's Hospital, Wilmington, Delaware, USA (J.E. Bennett, A.D. Thompson); Children's Minnesota, Minneapolis, Minnesota, USA (A.B. Kharbanda); Massachusetts General Hospital, Boston (J.A. Branda); Rhode Island Hospital, Providence, Rhode Island, USA (A.C. Garro)
\end{abstract}

DOI: https://doi.org/10.3201/eid2612.200920
In 2015, we founded Pedi Lyme Net, a pediatric Lyme disease research network comprising 8 emergency departments in the United States. Of 2,497 children evaluated at 1 of these sites for Lyme disease, 515 (20.6\%) were infected. This network is a unique resource for evaluating new approaches for diagnosing Lyme disease in children.

Children are disproportionally affected by Lyme disease, which is diagnosed in $\approx 300,000$ persons in the United States each year (1). Clinicians diagnose Lyme disease using a 2-tier examination of enzyme immunoassay (EIA) and immunoblot results. Current Lyme disease diagnostic tests have well-described limitations that include false negatives early in disease (3) and inability to distinguish between resolved, active, and recurrent infections (4). Clinicians must also wait several days for Lyme disease serologic results, a delay that might contribute to late or unnecessary treatment with antimicrobial drugs. The increased incidence of Lyme disease, limitations of current tests, and lack of studies in children demonstrate the need for a systematic approach to Lyme disease diagnosis in children.

Developing improved diagnostic techniques relies on biobanks of samples collected from patients with Lyme disease and clinical mimics (i.e., patients with similar signs and symptoms caused by non-Lyme illnesses). The US Centers for Disease Control and Prevention (Atlanta, GA, USA) curated the first Lyme disease biobank with samples from 86 adults with Lyme disease, 144 clinical mimics, and 203 healthy controls from 11 collection sites (5). The Study of Lyme Disease Immunology and Clinical Events (http://www.slicestudies. org) at the Johns Hopkins Lyme Disease Research Center (Baltimore, MD, USA) enrolled 40 adults with an erythema migrans (EM) lesion and followed up with patients for 1 year. The Lyme Disease Biobank, supported by the Bay Area Lyme Foundation, has enrolled 550 adults with Lyme disease evaluated at 7 primarycare collection sites (6). To date, none of these biobanks have included children or used emergency departments for enrollment.

In 2015, we founded Pedi Lyme Net, a pediatric Lyme disease research network comprising 8 emergency departments in a diverse range of areas to which Lyme disease is endemic. We conducted a prospective cohort study of children evaluated for Lyme at 1 of of these emergency departments (Appendix Figure 1, https://wwwnc.cdc.gov/EID/ article/26/12/20-0920-App1.pdf). The Pediatric Lyme Disease Biobank, housed at Boston Children's Hospital (Boston, MA, USA), stores and distributes the biosamples collected from enrolled children (7). 
Table. Characteristics of enrolled children with Lyme disease and clinical mimics, United States, 2015-2020*

\begin{tabular}{|c|c|c|c|}
\hline Characteristics & Lyme disease & Clinical mimics & $\mathrm{p}$ value \\
\hline Total & 515 & 1,982 & \\
\hline \multicolumn{4}{|l|}{ Demographics } \\
\hline Median age, y (IQR) & $8(6-11)$ & $9(5-14)$ & 0.02 \\
\hline \multicolumn{4}{|l|}{ Sex } \\
\hline$M$ & $345(67.0)$ & $1.048(52.9)$ & $<0.01$ \\
\hline $\mathrm{F}$ & $170(33.0)$ & $934(47.1)$ & \\
\hline \multicolumn{4}{|l|}{ Race } \\
\hline White & $438(85.0)$ & $1,482(74.8)$ & $<0.01$ \\
\hline Black & $42(8.2)$ & $255(12.9)$ & \\
\hline Asian & $8(1.6)$ & $53(2.7)$ & \\
\hline Pacific Islander & 0 & $3(0.1)$ & \\
\hline Native American & 0 & $2(0.1)$ & \\
\hline Other & $22(4.3)$ & $156(7.9)$ & \\
\hline Missing data & $5(1.0)$ & $31(1.6)$ & \\
\hline \multicolumn{4}{|l|}{ Ethnicity } \\
\hline Hispanic & $33(6.4)$ & $234(11.8)$ & $<0.01$ \\
\hline Non-Hispanic & $480(93.2)$ & $1,734(87.5)$ & \\
\hline Missing data & $2(0.4)$ & $14(0.7)$ & \\
\hline \multicolumn{4}{|l|}{ History } \\
\hline Presentation during peak Lyme season† & $343 / 515(66.6)$ & $1,187 / 1,982(59.9)$ & $<0.01$ \\
\hline Previous Lyme disease & $47 / 514(9.1)$ & $79 / 1,945(4.1)$ & $<0.01$ \\
\hline Tick bite within past year & $73 / 468(15.6)$ & $150 / 1,808(8.3)$ & $<0.01$ \\
\hline Fever & $176 / 507(34.7)$ & $732 / 1,959(37.4$ & 0.35 \\
\hline Headache & $152 / 510(29.8)$ & $760 / 1,926(39.5)$ & $<0.01$ \\
\hline \multicolumn{4}{|l|}{ Examination } \\
\hline Erythema migrans lesion & $54(10.5)$ & NA & NA \\
\hline Facial palsy & 59 (11.5) & $158(8.0)$ & $<0.01$ \\
\hline Lumbar puncture performed & $47(9.1)$ & $155(7.8)$ & 0.33 \\
\hline Meningitis & $21 / 47(44.7)$ & $57 / 155(36.8)$ & \\
\hline Arthritis (joint swelling) & $286(55.5)$ & $556(28.1)$ & $<0.01$ \\
\hline
\end{tabular}

*Values are no. (\%) except as indicated. NA, not applicable.

†June-October.

We describe enrolled children 1-21 years of age who underwent emergency department evaluation for Lyme disease during June 1, 2015-January 31, 2020 (Table). We obtained informed consent from parents/ guardians for study participation and child assent for those $\geq 8$ years of age. Informed consent documents were available in English and Spanish. We defined disease stage on the basis of signs and symptoms: early (i.e., single EM lesion), early disseminated (i.e., multiple EM lesions, cranial neuritis, meningitis, or carditis) or late (i.e., arthritis or arthralgia). In addition, as asymptomatic controls, we enrolled children undergoing intravenous cannulation for procedural sedation for fracture reduction or laceration repair without acute infectious symptoms. We implemented standard operating procedures at each of the participating sites (Appendix Table). All deidentified data were collected electronically with Research Electronic Data Capture housed at Harvard University (https:/ / catalyst.harvard.edu/services/redcap).

We defined Lyme disease on the basis of an EM lesion diagnosed by the treating clinician or positive serologic results with compatible symptoms. We took serum samples from all enrolled patients, including asymptomatic controls, and conducted a C6 EIA on each sample. If the EIA results were positive or equivocal, we also conducted a Western immunoblot interpreted using standard criteria (8). We considered a positive IgM immunoblot paired with a negative IgG immunoblot to be positive only if symptoms lasted $\leq 30$ days (10). We classified symptomatic children who tested negative for Lyme disease as clinical mimics. We compared characteristics of children with Lyme disease and mimics using the $\chi^{2}$ test for categorical variables and the Mann-Whitney test for continuous variables with SPSS Statistics 23.0 (IBM Corp., https://www.ibm.com).

We enrolled and obtained samples from 2,497 symptomatic and 377 asymptomatic control patients (Appendix Figure 2). Overall, 515 (20.6\% of symptomatic patients) had Lyme disease; of these children, $46(8.9 \%)$ had an EM lesion alone, 461 (89.5\%) had a positive 2-tier serology alone, and $8(1.6 \%)$ had both. Of the asymptomatic control patients, $4(1.1 \%)$ had positive 2-tier serology.

Our Pediatric Lyme Disease Biobank is unique because it includes biosamples from pediatric patients, clinical mimics, and diverse geographic regions. The samples are linked to demographic, clinical, laboratory, and treatment data about each patient. With $>2,800$ children enrolled, this biobank is a unique resource for researching Lyme disease diagnosis in children. 
Our biobank has a few limitations. First, we enrolled a convenience sample of children depending on the availability of study staff. However, in this study, the proportion of children with Lyme disease did not differ between enrolled and unenrolled but eligible patients. Second, some children with early or early-disseminated Lyme disease might have had false negative serologic results. However, we conducted follow-up to identify children who had initially negative 2-tier Lyme serologic results but tested positive within 30 days of enrollment. Finally, because our network includes only 8 enrollment sites, we were unable to include all regions to which Lyme disease is endemic.

\section{Acknowledgments}

We would like to thank patients and families who agreed to participate in the study.

This study received funding from Boston Children's Hospital and Global Lyme Alliance.

Interested collaborators should contact Pedi Lyme Net to discuss potential collaborations.

\section{About the Author}

Dr. Nigrovic is an associate professor of Pediatrics and Emergency Medicine at Harvard Medical School. Her research interests include the diagnosis of Lyme disease in children.

\section{References}

1. Hinckley AF, Connally NP, Meek JI, Johnson BJ, Kemperman MM, Feldman KA, et al. Lyme disease testing by large commercial laboratories in the United States. Clin Infect Dis. 2014;59:676-81. https://doi.org/10.1093/cid/ciu397

2. Wormser G-PP, Dattwyler R-JJ, Shapiro E-DD, Halperin JJ, Steere AC, Klempner MS, et al. The clinical assessment, treatment, and prevention of Lyme disease, human granulocytic anaplasmosis, and babesiosis: clinical practice guidelines by the Infectious Diseases Society of America. Clin Infect Dis. 2006;43:1089-134. https://doi.org/10.1086/508667

3. Branda JA, Body BA, Boyle J, Branson BM, Dattwyler RJ, Fikrig E, et al. Advances in serodiagnostic testing for Lyme disease are at hand. Clin Infect Dis. 2018;66:1133-9. https:/ / doi.org/10.1093/cid/cix943

4. Garro A, Bennett J, Balamuth F, Levas MN, Neville D, Branda JC, et al.; Pedi Lyme Net. Positive 2-tiered Lyme disease serology is uncommon in asymptomatic children living in endemic areas of the United States. Pediatr Infect Dis J. 2019;38:e105-7. https:/ / doi.org/10.1097/ INF.0000000000002157

5. Molins CR, Sexton C, Young JW, Ashton LV, Pappert R, Beard CB, et al. Collection and characterization of samples for establishment of a serum repository for Lyme disease diagnostic test development and evaluation. J Clin Microbiol. 2014;52:3755-3762. https:/ / doi.org/10.1128/ JCM.01409-14
6. Horn EJ, Dempsey G, Schotthoefer AM, Prisco UL, McArdle M, Gervasi SS, et al. The Lyme Disease Biobank: characterization of 550 patient and control samples from the East Coast and Upper Midwest of the United States. J Clin Microbiol. 2020;58:1-12.

7. Boston Children's Hospital. Pedi Lyme Net. 2020 [cited 2020 Aug 3]. http:/ / www.childrenshospital.org/research/ centers-departmental-programs/Pedi-Lyme-Net

8. Centers for Disease Control and Prevention. Recommendations for test performance and interpretation from the Second National Conference on Serologic Diagnosis of Lyme Disease. MMWR Morb Mortal Wkly Rep. 1995;44:590-1.

9. Nowakowski J, Schwartz I, Liveris D, Wang G, Aguero-Rosenfeld ME, Girao G, et al.; Lyme Disease Study Group. Laboratory diagnostic techniques for patients with early Lyme disease associated with erythema migrans: a comparison of different techniques. Clin Infect Dis. 2001;33:2023-7. https:/ / doi.org/10.1086/324490

10. Lantos PM, Lipsett SC, Nigrovic LE. False positive Lyme disease IgM immunoblots in children. J Pediatr. 2016;174:267269.e1. https:// doi.org/10.1016/j.jpeds.2016.04.004

Address for correspondence: Lise Nigrovic, Division of Emergency Medicine, Boston Children's Hospital, 300 Longwood Avenue, Boston, MA 02115, USA; email: lise.nigrovic@childrens.harvard.edu

\section{Transmission Electron Microscopy Confirmation of Orientia tsutsugamushi in Human Bile}

\author{
Yujeong Lee, ${ }^{1}$ Seung II Kim, ${ }^{1}$ Yoon-sun Yi, \\ Hayoung Lee, Joo-Hee Hwang, Edmond Changkyun \\ Park, Sangmi Jun, ${ }^{2}$ Chang-Seop Lee ${ }^{2}$ \\ Author affiliations: Korea Basic Science Institute, Cheongju, \\ South Korea (Y. Lee, S.I. Kim, Y.-s. Yi, H. Lee, E.C. Park, \\ S. Jun); Korea Research Institute of Chemical Technology, \\ Daejeon, South Korea (Y. Lee, S.I. Kim, E.C. Park, S. Jun); \\ University of Science and Technology, Daejeon (S.I. Kim, H. Lee, \\ E.C. Park); Jeonbuk National University, Jeonju, South Korea \\ (J.-H. Hwang, C.-S. Lee); Jeonbuk National University Hospital, \\ Jeonju (J.-H. Hwang, C.-S. Lee)
}

${ }^{1}$ These authors contributed equally to this article.

${ }^{2}$ These authors were co-principal investigators. 